\title{
Sympathetic Nervous System Control of Carbon Tetrachloride-Induced Oxidative Stress in Liver through $\alpha$-Adrenergic Signaling
}

\author{
Jung-Chun Lin,, ${ }^{1,2}$ Yi-Jen Peng, ${ }^{1,3}$ Shih-Yu Wang,, ${ }^{3,4}$ Mei-Ju Lai, ${ }^{3}$ Ton-Ho Young, \\ Donald M. Salter, ${ }^{6}$ and Herng-Sheng Lee ${ }^{1,3,4}$ \\ ${ }^{1}$ Graduate Institute of Medical Sciences, National Defense Medical Center and Department of Pathology, Tri-Service General Hospital, \\ 325 Section 2, Cheng-gong Road, Neihu, Taipei 114, Taiwan \\ ${ }^{2}$ Division of Gastroenterology and Hepatology, Department of Internal Medicine, Tri-Service General Hospital, \\ National Defense Medical Center, Taipei, Taiwan \\ ${ }^{3}$ Department of Pathology, Tri-Service General Hospital, National Defense Medical Center, Taipei, Taiwan \\ ${ }^{4}$ Department of Pathology and Laboratory Medicine, Kaohsiung Veterans General Hospital, No. 386, Dazhong 1st Road, \\ Zuoying District, Kaohsiung 81362, Taiwan \\ ${ }^{5}$ Division of Gastroenterology, Department of Internal Medicine, Cardinal Tien Hospital, Fu Jen Catholic University, Taipei, Taiwan \\ ${ }^{6}$ Center for Molecular Medicine, MRC IGMM, University of Edinburgh, Edinburgh, UK
}

Correspondence should be addressed to Herng-Sheng Lee; herngsheng131419@gmail.com

Received 6 May 2015; Revised 17 August 2015; Accepted 29 September 2015

Academic Editor: Karina R. Gordillo

Copyright (C) 2016 Jung-Chun Lin et al. This is an open access article distributed under the Creative Commons Attribution License, which permits unrestricted use, distribution, and reproduction in any medium, provided the original work is properly cited.

\begin{abstract}
In addition to being the primary organ involved in redox cycling, the liver is one of the most highly innervated tissues in mammals. The interaction between hepatocytes and sympathetic, parasympathetic, and peptidergic nerve fibers through a variety of neurotransmitters and signaling pathways is recognized as being important in the regulation of hepatocyte function, liver regeneration, and hepatic fibrosis. However, less is known regarding the role of the sympathetic nervous system (SNS) in modulating the hepatic response to oxidative stress. Our aim was to investigate the role of the SNS in healthy and oxidatively stressed liver parenchyma. Mice treated with 6-hydroxydopamine hydrobromide were used to realize chemical sympathectomy. Carbon tetrachloride $\left(\mathrm{CCl}_{4}\right)$ injection was used to induce oxidative liver injury. Sympathectomized animals were protected from $\mathrm{CCl}_{4}$ induced hepatic lipid peroxidation-mediated cytotoxicity and genotoxicity as assessed by 4-hydroxy-2-nonenal levels, morphological features of cell damage, and DNA oxidative damage. Furthermore, sympathectomy modulated hepatic inflammatory response induced by $\mathrm{CCl}_{4}$-mediated lipid peroxidation. $\mathrm{CCl}_{4}$ induced lipid peroxidation and hepatotoxicity were suppressed by administration of an $\alpha$-adrenergic antagonist. We conclude that the SNS provides a permissive microenvironment for hepatic oxidative stress indicating the possibility that targeting the hepatic $\alpha$-adrenergic signaling could be a viable strategy for improving outcomes in patients with acute hepatic injury.
\end{abstract}

\section{Introduction}

The liver is one of the most highly innervated tissues in mammals. The interaction between hepatocytes and sympathetic, parasympathetic, and peptidergic nerve fibers through a variety of neurotransmitters and signaling pathways is recognized as being important in the regulation of hepatocyte function and hepatic response to injury [1]. Studies of hepatic architecture identify adrenergic nerve fibers extending from perivascular plexus in the portal space into the lobule [2]. Sympathetic nervous system (SNS) transmission to hepatocytes occurs through release of norepinephrine and epinephrine as neurotransmitters from intrahepatic nerve endings and by delivery as hormones from adrenal glands. In addition to being important for a range of functions such as regulating hepatic circulation, metabolism, and bile 
formation the SNS is also known to modulate both liver regeneration and fibrosis [3-5].

Potential associations between the SNS and oxidative stress are indicated from previous studies. Hepatic monoamine oxidases catalyze oxidative deamination of catecholamines such as norepinephrine and epinephrine. During this process hydrogen peroxide $\left(\mathrm{H}_{2} \mathrm{O}_{2}\right)$ is generated and further converted to water by glutathione peroxidase during which glutathione is utilized [6]. Thus, oxidation of catecholamines is a source of reactive oxygen species (ROS) [7]. Long-term elevation of epinephrine can deplete hepatic glutathione as epinephrine both decreases the rate of glutathione synthesis in the liver and increases the rate of glutathione release from the liver whilst decreasing the rate of recycling of oxidized glutathione [8-10]. Similarly, epinephrine stimulates $\mathrm{H}_{2} \mathrm{O}_{2}$ production via cyclic $3^{\prime}-5^{\prime}$-adenosine monophosphates in macrophages [11]. Intense physical work is known to increase sympathetic activity and ROS production in the rodent heart [12]. The knowledge that $\beta$-adrenergic stimulation is the main driver of ROS generation in mitochondria [13] has indicated the use of $\beta$-adrenergic receptor blockers to reduce oxidative stress in cardiac failure $[14,15]$.

Although these studies clearly suggest a role for catecholamines in the modulation of oxidative stress, whether the SNS affects oxidative stress in the liver has yet to be established. $\mathrm{CCl}_{4}$ is a classic model compound for inducing free radical damage in the liver $[16,17]$, being metabolized to form trichloromethyl and trichloromethyl peroxy radicals which covalently bind to proteins, lipids, and nucleic acids to initiate lipid peroxidation, generate 4-hydroxy-2-nonenal (4-HNE), and thus induce liver damage [17]. This model is also useful for characterization of xenobiotic-induced hepatotoxicity, screening of hepatoprotective effects of drugs, and studying mechanisms of human liver injury $[18,19]$. An ablation of the SNS exerts a protective effect against $\mathrm{CCl}_{4}$ induced acute liver injury in mice [20]. In the current study peripheral injection of the neurotoxin 6-hydroxydopamine hydrobromide (6OHDA) was used to induce chemical sympathectomy and the effects on acute $\mathrm{CCl}_{4}$ induced hepatic lipid peroxidation were assessed. We also tested the hypothesis that adrenergic signaling is required for control of the oxidative stress in hepatocytes after acute $\mathrm{CCl}_{4}$ exposure. The observation that chemical sympathectomy or treatment with the $\alpha$ adrenoreceptor antagonist has profound inhibitory effects on $\mathrm{CCl}_{4}$ induced hepatic oxidative injury has important implications for understanding of how the response to liver injury may be controlled and, on a clinically applicable basis, indicate potential novel strategies for management of acute or, indeed, chronic liver injury.

\section{Materials and Methods}

2.1. Animal Care. Male C57Bl/6JNarl mice aged 8 weeks were obtained from the National Laboratory Animal Center in Taipei, Taiwan. They were maintained under controlled conditions $\left(22 \pm 1^{\circ} \mathrm{C}\right.$ and $12 \mathrm{~h}$ day/night rhythm) and fed standard laboratory food.
2.2. Chemical Sympathectomy and Antagonists. Mice were intraperitoneally injected with $100 \mathrm{mg} \mathrm{kg}^{-1}$ 6-OHDA (Sigma, St. Louis, MO, USA) in $0.1 \%$ ascorbic acid (Sigma) in phosphate buffered saline (PBS, Gibco, Gaithersburg, MD) daily over 5 consecutive days. Peripheral administration of 6OHDA results in a "chemical sympathectomy" by depleting sympathetic fibers [20] and has previously been found to induce an $85 \%$ decrease in norepinephrine levels in the liver [21]. Control mice received injections of $0.1 \%$ ascorbic acid in PBS. One day following the final treatment with 6-OHDA, mice were subjected to the acute oxidative liver injury protocol described below. Phentolamine $\left(10 \mathrm{mg} \mathrm{kg}^{-1}\right)$ and nadolol $\left(20 \mathrm{mg} \mathrm{kg}^{-1}\right)$ were injected in $0.9 \%$ saline daily intraperitoneally, commencing 5 days before $\mathrm{CCl}_{4}$ administration, while control mice were injected with $0.9 \%$ saline vehicle.

2.3. Acute Oxidative Liver Injury Induced by $\mathrm{CCl}_{4}$. Mice were injected intraperitoneally with a single dose of $\mathrm{CCl}_{4}$ (Sigma) (12.5\% in olive oil (Sigma), $2 \mathrm{~mL} \mathrm{~kg}^{-1}$ ). Control groups were treated with vehicle $\left(2 \mathrm{~mL} \mathrm{~kg}{ }^{-1}\right.$ of olive oil). At $24 \mathrm{~h}$ after $\mathrm{CCl}_{4}$ or vehicle treatment, mice were weighed and then euthanized by carbon dioxide asphyxiation. Blood was collected from the heart for analysis of serum AST, ALT, LDH, and ALP by standard enzymatic methods. The liver was then removed, weighed, and processed for further analysis as described.

\subsection{Immunostaining and Assessment of Hepatocyte Nuclear} Morphology. Samples of liver from mice with or without chemical sympathectomy were embedded in optimum cutting temperature (OCT) (Tissue-Tek, Sakura, CA, USA) compound and quickly frozen. Five $\mu \mathrm{m}$ thick sections were cut and fixed with methanol/acetone. Immunohistochemistry for identification of sympathetic nerve fibers was performed with a primary antibody against tyrosine hydroxylase (the key enzyme for norepinephrine production in sympathetic nerve endings, Millipore, Billerica, MA, USA) and an Alexa 488 conjugated secondary antibody (against rabbit IgG, Invitrogen Corporation, Carlsbad, CA, USA). Following a final incubation for $1 \mathrm{~h}$ with propidium iodide $(50 \mu \mathrm{g} / \mathrm{mL})$ (Invitrogen) sections were viewed with a Zeiss LSM 510 Meta inverted confocal microscope using a LD-Achroplan 20x lens.

For assessment of nuclear morphology sections were washed twice in TBST (12.5 mM Tris/HCl, pH 7.6, $137 \mathrm{mM}$ $\mathrm{NaCl}$, and $0.1 \%$ Tween 20 ) before $4^{\prime}, 6$-diamidino-2-phenylindole dihydrochloride (DAPI) (Sigma) diluted 1:10,000 in PBS for $5 \mathrm{~min}$ at room temperature. Slides were mounted with glycerin, coverslipped, and examined using a fluorescence microscope (Olympus BX-51).

2.5. Histological Analysis of the Liver. The liver left lateral lobes were removed and fixed in $10 \%$ buffered formalin before standard tissue processing, embedding in paraffin wax, and cutting into $5 \mu \mathrm{m}$ sections which were stained with hematoxylin and eosin. Histological examination was performed in a blinded fashion by three experienced pathologists. The severity of hepatic injury was scored as described by Camargo et al. [22] according to the following criteria: 0, minimal 
or no evidence of injury; 1, mild injury with cytoplasmic vacuolization and focal nuclear pyknosis; 2 , moderate to severe injury with extensive nuclear pyknosis, cytoplasmic hypereosinophilia, and loss of intercellular borders; and 3, severe necrosis with disintegration of hepatic cords, hemorrhage, and neutrophil infiltration. Areas of hepatocyte necrosis were expressed as the percentage of damaged liver architecture, measured in 10 randomly selected high-power fields per section using ImageJ software (version $1.48 \mathrm{u}$, US National Institutes of Health).

2.6. Estimation of Hepatic Lipid Peroxidation Assay. Samples of liver were homogenized on ice in PBS containing butylhydroxytoluene and centrifuged at $10,000 \mathrm{~g}\left(4^{\circ} \mathrm{C}, 5 \mathrm{~min}\right) .4-$ HNE adducts were measured in supernatants with the OxiSelect HNE-His adduct enzyme-linked immunosorbent assay (ELISA) kit (Cell Biolabs, Inc., San Diego, CA) in accordance with the manufacturers' instructions. The concentration of 4HNE adducts was normalized per microgram of total protein, the concentration of the latter being determined by the Lowry method.

2.7. Transmission Electron Microscopy. Liver tissues were fixed in a mixture of $4 \%$ paraformaldehyde and $0.5 \%$ glutaraldehyde in PBS, $\mathrm{pH}$ 7.4, and prepared routinely for transmission electron microscopy with final embedding in LR white resin. Ultrathin sections $(70-80 \mathrm{~nm})$ were cut, placed on a nickel grid, and then examined under a Hitachi H-600 transmission electron microscope.

2.8. 8-Hydroxy-2-deoxyguanosine (8-OHdG) Assay. Total DNA from liver was extracted using the Qiagen DNeasy blood and tissue kit according to the manufacturer's instructions (Qiagen, Valencia, CA, USA). A NanoDrop 1000 spectrophotometer (Thermo Fisher, Pittsburgh, PA, USA) was utilized to measure DNA purity. Briefly, $\mathrm{pH}$ of DNA $(25 \mu \mathrm{g})$ was adjusted to 5.2 with $3 \mathrm{M}$ sodium acetate. The DNA reaction mixture was subjected to $1 \mu \mathrm{L}$ of nuclease $\mathrm{P} 1(1 \mathrm{U} / \mu \mathrm{L})$ digestion for $2 \mathrm{~h}$ at $37^{\circ} \mathrm{C}$. After $2 \mathrm{~h}$ of incubation, $15 \mu \mathrm{L}$ of $1 \mathrm{M}$ Tris- $\mathrm{HCl}(\mathrm{pH} 8.0)$ was used to bring the $\mathrm{pH}$ back to 7.4 , followed by treatment with $5 \mu \mathrm{L}$ of alkaline phosphatase ( $1 \mathrm{U} / \mu \mathrm{L}$ stock) for $1 \mathrm{~h}$. The reaction mixture was centrifuged for $5 \mathrm{~min}$ at $6,000 \mathrm{~g}$, and the supernatant was collected for the 8-OHdG assay using the OxiSelect oxidative DNA damage ELISA kit (Cell Biolabs, Inc., San Diego, CA, USA) according to the manufacturer's instructions. Known standards were also included in the assay to allow accurate quantitation. Six livers were used for each experimental group.

2.9. Cytokines/Chemokines Antibody Array. Livers were homogenized in lysis buffer (kit component) and then centrifuged to collect the supernatant to detect 40 cytokines/chemokines on the RayBio Mouse Inflammation Antibody Array 1 membrane (RayBiotech, Inc., Norcross, GA, USA), according to the manufacturer's protocol. We pooled six samples per group to obtain $300 \mu \mathrm{g}$ total proteins per membrane (one membrane for each group). The membranes were blocked in $2 \mathrm{~mL}$ of blocking buffer for $30 \mathrm{~min}$ and then incubated with pooled supernatant at room temperature for $2 \mathrm{~h}$. The samples were then decanted from each container, and the membranes were washed three times with $2 \mathrm{~mL}$ of wash buffer I, followed by two washes with $2 \mathrm{~mL}$ of $1 \mathrm{x}$ wash buffer II at room temperature with shaking. The membranes were incubated in 1:250-diluted biotin-conjugated primary antibodies at room temperature for $2 \mathrm{~h}$ and washed as above before incubation in 1:1000-diluted horseradish peroxidase-conjugated streptavidin. After incubation in horseradish peroxidase-conjugated streptavidin for $1 \mathrm{~h}$, the membranes were washed thoroughly and exposed to a peroxidase substrate for $5 \mathrm{~min}$ in the dark before imaging. The membranes were scanned and analyzed by using TotalLab Quant software (TotalLab Ltd., Newcastle upon Tyne, UK). Proteins with $>2$-fold differences in their expression levels between the saline $+\mathrm{CCl}_{4}$ group and the saline + olive oil group were considered as differentially expressed.

2.10. Statistical Analysis. The results were expressed as mean \pm standard deviation (SD). Results were analyzed using Student's $t$-test for unpaired data. The statistical significance level was a $p$ value of $<0.05$.

\section{Results}

3.1. Alleviation Effect of Chemical Sympathectomy on Lipid Peroxidation in $\mathrm{CCl}_{4}$ Induced Hepatic Injury. Tyrosine hydroxylase-expressing fibers were readily identified in the border of periportal areas of saline-treated mice but were essentially absent in 6-OHDA-treated animals (Supplementary Data, Figure S1 in Supplementary Material available online at http://dx.doi.org/10.1155/2016/3190617) confirming successful hepatic sympathectomy. There was no hepatic necrosis in saline- or 6-OHDA-treated mice treated with olive oil alone. The extent of $\mathrm{CCl}_{4}$ induced hepatic necrosis was significantly greater in saline-treated mice than in 6-OHDAtreated mice $(32.1 \pm 8.6 \%$ versus $9.2 \pm 4.4 \%, p=0.0007)$ (Supplementary Data, Figures S2(a) and S2(b)). Similarly the severity score of hepatic injury was significantly greater (Supplementary Data, Figure S2(c), $p<0.0001$ ) in the saline $+\mathrm{CCl}_{4}$ group $(2.7 \pm 0.5)$ when compared to the 6$\mathrm{OHDA}+\mathrm{CCl}_{4}$ group $(1.5 \pm 0.5)$. Biochemical markers of liver injury, including aspartate aminotransferase (AST; 4,115 \pm $1,755$ versus $17,830 \pm 3,078 \mathrm{IU} / \mathrm{L}, p<0.0001)$, alanine aminotransferase (ALT; 7,809 $\pm 2,527$ versus $15,519 \pm 4,678$, $p=0.0052$ ), alkaline phosphatase (ALP; $56 \pm 26$ versus $128 \pm$ $11, p=0.0013$ ), and lactate dehydrogenase (LDH; 11,139 \pm 5,496 versus $28,764 \pm 8,063, p=0.0001$ ) levels $24 \mathrm{~h}$ after $\mathrm{CCl}_{4}$ treatment were lower in serum from 6-OHDA-treated mice compared to the saline-treated group (Supplementary Data, Table S1).

As secondary products during lipid peroxidation, malondialdehyde appears to be the most mutagenic product of lipid peroxidation, whereas $4-\mathrm{HNE}$ is the most toxic and considered as "one of major generators of oxidative stress" and a "major lipid peroxidation product" [23-25]. Thus, we investigated ROS-induced lipid damage as measured by changes in 4-HNE levels in the livers of saline- and 6-OHDAtreated mice $24 \mathrm{~h}$ after $\mathrm{CCl}_{4}$ administration (Table 1). As 
TABLE 1: Effect of sympathectomy on $\mathrm{CCl}_{4}$ induced lipid peroxidation in liver.

\begin{tabular}{|c|c|c|c|c|}
\hline Parameter & $\begin{array}{c}\text { Saline + olive oil } \\
\quad(n=6)\end{array}$ & $\begin{array}{l}\text { 6-OHDA + olive oil } \\
(n=6)\end{array}$ & $\begin{array}{c}\text { Saline }+\mathrm{CCl}_{4} \\
(n=6)\end{array}$ & $\begin{array}{c}6-\mathrm{OHDA}+\mathrm{CCl}_{4} \\
(n=6)\end{array}$ \\
\hline 4-Hydroxy-2-nonenal (4-HNE, $\mu \mathrm{g} / \mu \mathrm{g}$ protein) & $0.23 \pm 0.02$ & $0.18 \pm 0.02^{* *}$ & $0.33 \pm 0.07^{*}$ & $0.23 \pm 0.03^{\#,+\dagger}$ \\
\hline
\end{tabular}

The results are presented as mean $\pm \mathrm{SD}$.

$*$ denotes significant differences compared with the saline + olive oil group $(p<0.05)$.

$* *$ denotes significant differences compared with the saline + olive oil group $(p<0.01)$.

\#\# denotes significant differences compared with the saline $+\mathrm{CCl}_{4}$ group $(p<0.01)$.

$\dagger \dagger$ denotes significant differences compared with the olive oil + 6-OHDA group $(p<0.001)$.

expected, 4-HNE was elevated in the livers of saline-treated mice $24 \mathrm{~h}$ after $\mathrm{CCl}_{4}$ treatment $(p=0.0122)$. This increase in lipid peroxidation was blocked when mice were treated with 6-OHDA prior to $\mathrm{CCl}_{4}(p=0.0053)$.

\subsection{Protective Effect of Chemical Sympathectomy on the Ultra-} structure of Hepatocyte Injury. Elevation in lipid peroxidation levels has been reported to correlate with ultrastructural changes in hepatocytes following $\mathrm{CCl}_{4}$ exposure since 4HNE can promote organelle damage [25-27]. In the current study the ultrastructure of hepatocytes was normal in the olive oil-treated groups (Figures 1(a), 1(b), 1(e), and 1(f)). Twenty-four hours after $\mathrm{CCl}_{4}$ administration, ultrastructural changes including expansion of the perinuclear space with a pyknotic condensed nucleus, increased number and size of lipid globules, glycogen loss, and mitochondrial swelling with loss of cristae in addition to dilation of the cisternae of rough endoplasmic reticulum were evident (Figures 1(c) and $1(\mathrm{~g}))$. In comparison to the saline $+\mathrm{CCl}_{4}$ mice, the number and size of lipid globules were decreased and glycogen deposits were readily identifiable within hepatocytes in the 6$\mathrm{OHDA}+\mathrm{CCl}_{4}$ group. Similarly the organelle and cytoplasmic structures appeared preserved from the deleterious effects of $\mathrm{CCl}_{4}$ (Figures $1(\mathrm{~d})$ and $1(\mathrm{~h})$ ).

3.3. Attenuation Effect of Chemical Sympathectomy on Hepatic Nuclear Damage. Lipid peroxidation products, in particular, 4-HNE, are known to promote hepatocyte nuclear loss or injury $[24,27,28]$ which can be visualized by DAPI staining [29]. The nuclei in hepatocytes of olive oil alone-treated mice were round and emitted even blue fluorescence (Figure 2). In the necrotic pericentral region livers of saline-treated mice $24 \mathrm{~h}$ after $\mathrm{CCl}_{4}$ administration nuclei were absent, condensed, or fragmented. 6-OHDA effectively preserved the integrity and morphology of hepatic nuclei in $\mathrm{CCl}_{4}$-treated mice (Figure 2).

3.4. Inhibition Action of Chemical Sympathectomy on Oxidative DNA Damage in Liver. Since 4-HNE also has high capability of reaction with DNA to cause DNA damage [25, 30], we examined whether sympathectomy attenuates liver oxidative DNA damage by analyzing $8-\mathrm{OHdG}$ content in hepatocyte. The level of $8-\mathrm{OHdG}$ in $\mathrm{CCl}_{4}$-treated livers without sympathectomy was increased by $94 \%$ when compared with that in olive oil-treated livers without sympathectomy (Figure 3, $p=0.0092$ ). Pretreatment with 6-OHDA, on the other hand, abrogated this increase $(p=0.0113)$. There was no significant difference in levels of 8-OHdG between the 6-OHDA + olive oil group and saline + olive oil group (Figure 3).

3.5. Analysis of Cytokine and Chemokine Protein Profiling in Livers. It is known that 4 -HNE plays a role as mediator of inflammatory processes with interactions with the cytokine networks [31-33]. In the current study we investigated the inflammatory response using a multiplex of 40 cytokines and chemokines. The results are shown in Figure 4. Following administration of $\mathrm{CCl}_{4}$ there was increased expression of a number of cytokines including IL- $\alpha(2.28$-fold, $p=0.0192)$, IL-10 (3.64-fold, $p=0.0070)$, leptin (9.27-fold, $p=0.0496$ ), tissue inhibitor of metalloproteinase-2 (TIMP-2, 2.90-fold, $p=0.0087$ ), soluble tumor necrosis factor receptor I (sTNFR $\mathrm{I}$, 3.62-fold, $p=0.0228)$, and granulocyte-macrophage colony-stimulating factor (GM-CSF, 5.58-fold, $p=0.0019$ ). There was also an increase in expression of 5 inflammationassociated chemokines. These were CCL3 (3.80-fold, $p=$ 0.0243), CCL5 (2.42-fold, $p=0.0153)$, CCL9 (3.57-fold, $p=0.0064)$, CCL11 (3.79-fold, $p=0.0344)$, and CXCL11 (6.71-fold, $p=0.0057)$. With chemical sympathectomy, in the absence of $\mathrm{CCl}_{4}$, there was reduction of protein levels of CCL5 (0.66-fold, $p=0.0022)$ and CCL9 (0.54-fold, $p=$ 0.0083 ) when compared with the saline + olive oil group but no significant change in the levels of other cytokines and chemokines was evident. Pretreatment with 6-OHDA inhibited the increase in hepatic cytokine and chemokine levels induced by $\mathrm{CCl}_{4}$.

3.6. Hepatoprotective and Antioxidant Effects of $\alpha$-Adrenergic Blockade against $\mathrm{CCl}_{4}$ Induced Oxidative Damage. Our findings strongly implicate an important role for the SNS in modulating $\mathrm{CCl}_{4}$ induced oxidative stress in liver, based strictly on 6-OHDA ablation of the peripheral SNS. However, it is unclear whether 6-OHDA could affect other cell types, for example, hepatocytes, in mice and through an alternative route directly or indirectly affect oxidative stress or the hepatic antioxidant status. To address this concern, we treated mice with drugs that selectively block $\alpha$ - or $\beta$-adrenergic receptors. Phentolamine, an $\alpha$-blocker, and nadolol, a $\beta$-blocker, were delivered intraperitoneally over 5 consecutive days before injection with $\mathrm{CCl}_{4}$. Nadolol had no significant effect on hepatic injury and antioxidant status (Table 2 ), indicating that $\beta$-adrenergic stimulation may not enhance or suppress hepatic oxidative stress responses to $\mathrm{CCl}_{4}$. Strikingly, phentolamine enhanced antioxidant status 


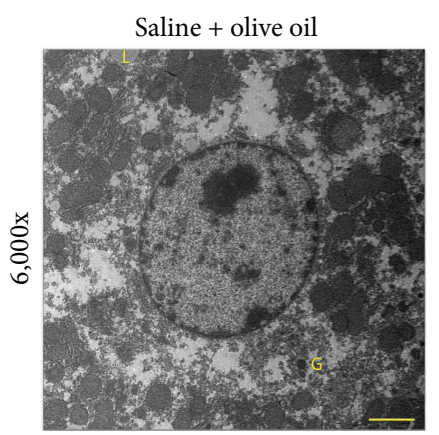

(a)

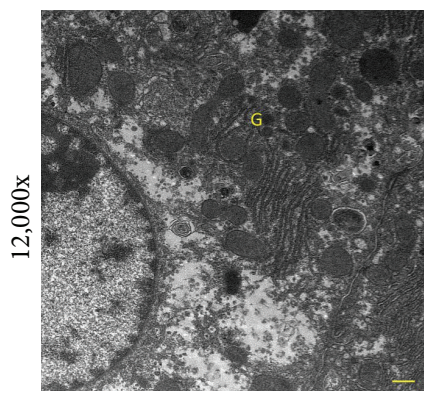

(e)

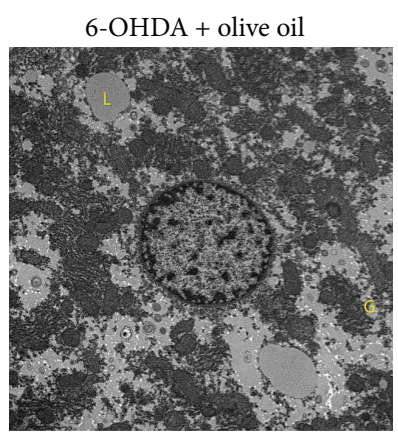

(b)

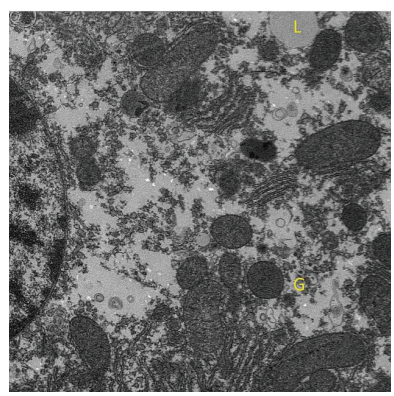

(f)

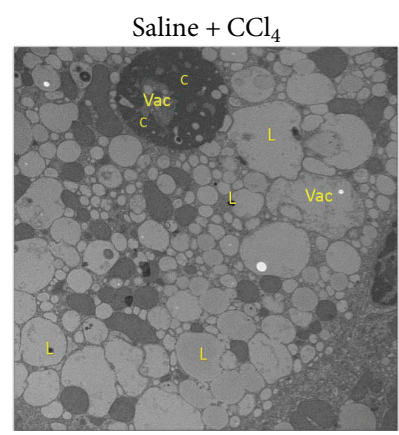

(c)

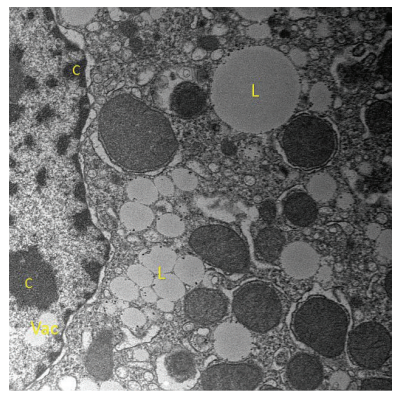

(g)

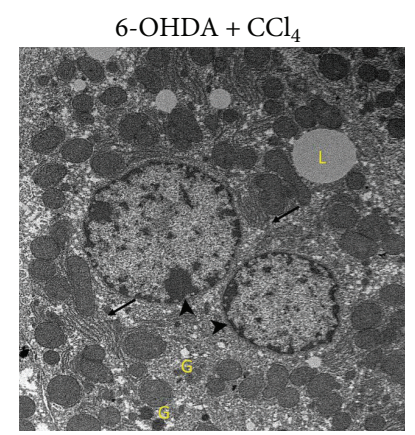

(d)

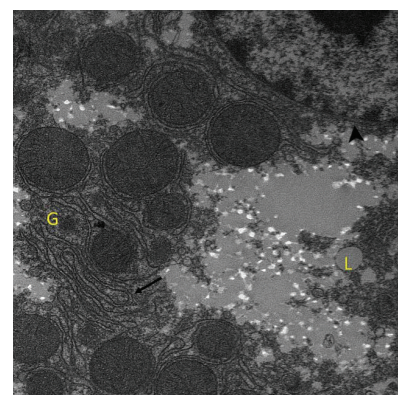

(h)

FIGURE 1: Effect of 6-OHDA on $\mathrm{CCl}_{4}$ induced changes on hepatocyte morphology. Representative micrographs of transmission electron microscopy (magnification 6,000x or 12,000x) in the liver tissues. (a and e) The saline + olive oil group; (b and f) the 6-OHDA + olive oil group; (c and g) the saline $+\mathrm{CCl}_{4}$ group; and $(\mathrm{d}$ and $\mathrm{h})$ the $6-\mathrm{OHDA}+\mathrm{CCl}_{4}$ group. Arrows denote rough endoplasmic reticulum. Arrowheads denote perinuclear space. C, chromatin; G, glycogen deposits; L, lipid drops; Vac, vacuolization. Scale bar denotes $100 \mathrm{~nm}$ in (a)-(d) and $500 \mathrm{~nm}$ in (e)-(h).

TABLE 2: Hepatic lipid peroxidation and serum biochemical markers in mice after 24 hours of $\mathrm{CCl}_{4}$ treatment with or without pretreatment of $\alpha$-adrenergic blocker or $\beta$-adrenergic blocker.

\begin{tabular}{lccc}
\hline Parameter & $\begin{array}{c}\text { Saline }+\mathrm{CCl}_{4} \\
(n=4)\end{array}$ & $\begin{array}{c}\text { Phentolamine }+\mathrm{CCl}_{4} \\
(n=4)\end{array}$ & $\begin{array}{c}\mathrm{Nadolol}+\mathrm{CCl}_{4} \\
(n=4)\end{array}$ \\
\hline 4-Hydroxy-2-nonenal (4-HNE, $\mu \mathrm{g} / \mu \mathrm{g}$ protein) & $0.34 \pm 0.04$ & $0.25 \pm 0.01^{*}$ & $0.28 \pm 0.02$ \\
Aspartate transaminase (AST, IU/L) & $16,695 \pm 5,203$ & $6,038 \pm 3,320^{*}$ & $13,571 \pm 5,758$ \\
Alanine transaminase (ALT, IU/L) & $14,559 \pm 3,268$ & $7,318 \pm 3,799^{*}$ & $10,830 \pm 4,381$ \\
Alkaline phosphatase (ALP, IU/L) & $131 \pm 14$ & $106 \pm 21^{*}$ & $140 \pm 31$ \\
Lactate dehydrogenase (LDH, IU/L) & $30,656 \pm 9,387$ & $8,994 \pm 5,986^{*}$ & $17,483 \pm 10,584$ \\
\hline
\end{tabular}

The results are presented as mean $\pm \mathrm{SD}$.

$*$ denotes significant differences compared with the saline $+\mathrm{CCl}_{4}$ group $(p<0.05)$.

in liver (Table 2, $p=0.0238$ ) and suppressed both the extent of hepatic necrosis $(11.62 \pm 2.76 \%$ versus $27.55 \pm 12.60 \%$, $p=0.0009)$ (Figure 5) and serum levels of AST $(p=0.0478)$, $\operatorname{ALT}(p=0.0387), \operatorname{ALP}(p=0.0346)$, and LDH $(p=0.0247)$ (Table 2) following $\mathrm{CCl}_{4}$ administration. Pretreatment with phentolamine abrogated the increased level of 8 -OHdG in $\mathrm{CCl}_{4}$-treated livers $(p=0.0193)$. There was no significant difference in levels of $8-\mathrm{OHdG}$ between the nadolol $+\mathrm{CCl}_{4}$ group and saline $+\mathrm{CCl}_{4}$ group (Figure 5(c)). The magnitude of the effect was similar to that induced by 6-OHDA treatment, pointing to an important role in SNS activation of $\alpha$-adrenergic receptors in regulating antioxidant status in liver.

\section{Discussion}

In the current study we show that the SNS has major roles in regulating lipid peroxidation, oxidative DNA damage, and proinflammatory cytokine production in the liver associated with $\mathrm{CCl}_{4}$ toxicity with chemical sympathectomy essentially preventing the major hepatotoxic effects seen within $24 \mathrm{~h}$ of $\mathrm{CCl}_{4}$ administration. We also present that $\alpha$-adrenergic signaling is required for control of the oxidative stress in hepatocytes after acute $\mathrm{CCl}_{4}$ exposure.

The changes of hepatocyte ultrastructure identified in the current study following $\mathrm{CCl}_{4}$ administration are in line with previous observations [26] and are likely to be the result of 

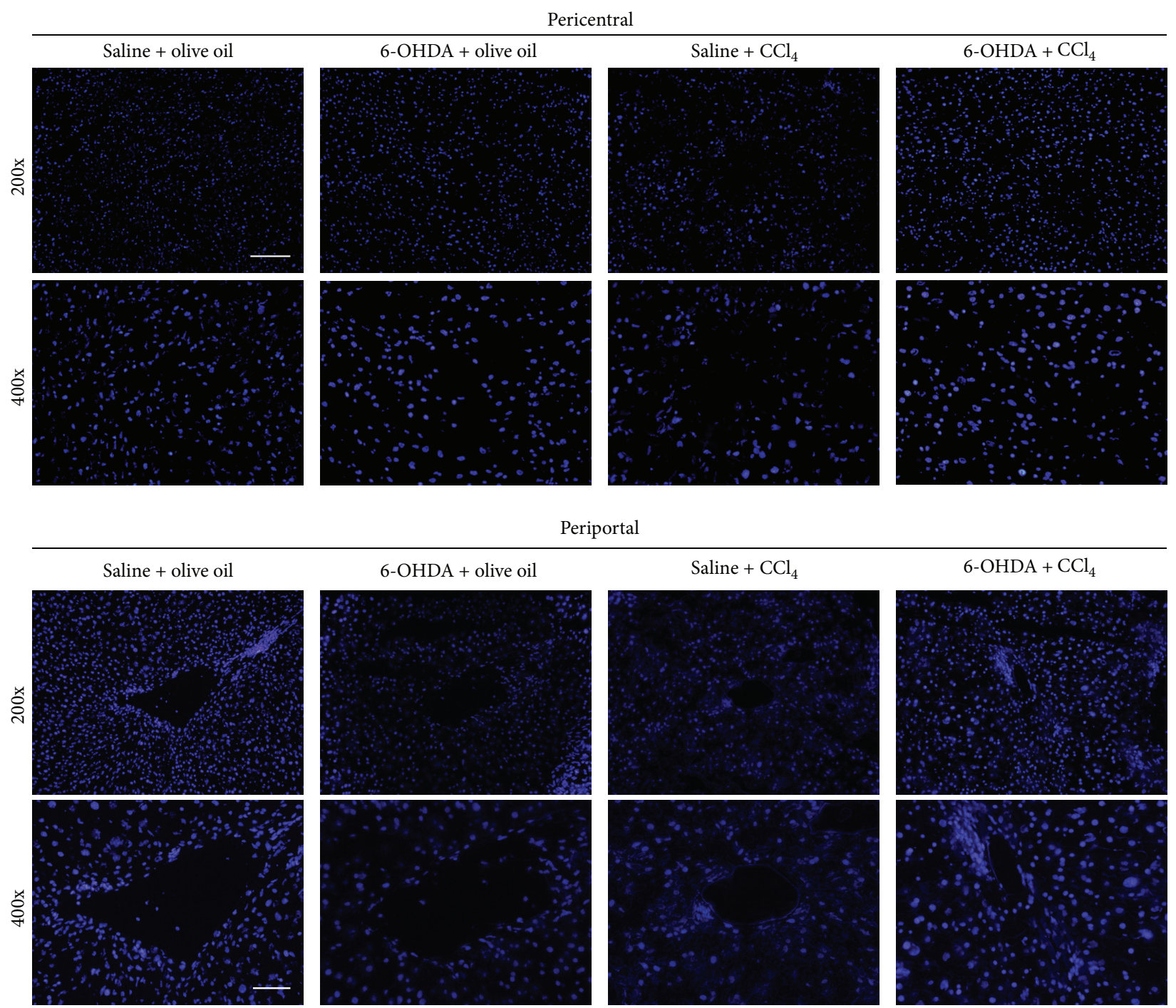

FIGURE 2: Effect of 6-OHDA on $\mathrm{CCl}_{4}$ induced changes in hepatocyte nuclei. Representative micrographs of DAPI stained nuclei (magnification 200x or 400x) in the liver tissues. Typical images were selected from each experimental group (original magnification 200x or $400 \mathrm{x})$. Scale bar $=100 \mu \mathrm{m}$ in $200 \mathrm{x}$ and $50 \mu \mathrm{m}$ in $400 \mathrm{x}$.

damage to cellular and organelle membrane structure caused by lipid peroxidation $[25,27]$. As chemical sympathectomy prevents these changes it is probable that sympathectomy supports the antioxidant defense system, maintaining membrane integrity. Sympathectomy also attenuated $\mathrm{CCl}_{4}$ toxicity characterized by the appearance of dysfunctional hepatic nuclei which arise as a result of enhanced lipid peroxidation $[24,27,28]$ further supporting the idea that the mode of action of the beneficial effect of sympathectomy is through reducing oxidative stress. Similarly, the observation that 6OHDA treatment inhibited oxidative stress-mediated DNA damage in $\mathrm{CCl}_{4}$-treated mice suggests that sympathectomy, at least in part, may attenuate oxidative stress-induced DNA damage through the inhibition of lipid peroxidation and the reduction of 4 -HNE generation because 4 -HNE is biologically reactive and known to cause DNA damage $[25,30]$.

The cytokine/chemokine array data also demonstrate an inhibitory effect of chemical sympathectomy on $\mathrm{CCl}_{4}$ induced hepatic proinflammatory responses. $\mathrm{CCl}_{4}$ induced production of inflammation-associated cytokines (IL- $1 \alpha$, IL10, leptin, TIMP-2, and sTNFR I) in the liver, in part a consequence of combined lipid peroxidation [31-33] and hepatocyte necrosis [34], results in an immunostimulatory environment $[16,35,36]$. Presumably the inhibitory effects of sympathectomy on $\mathrm{CCl}_{4}$ induced liver cell damage were sufficient to prevent activation of inflammatory cascades. It may also be possible that the SNS has a direct regulatory effect on resident Kupffer [37] and stellate cells [38] within the liver. We also identified an effect of sympathectomy on elevation of hepatic leptin following $\mathrm{CCl}_{4}$ induced injury. There is increasing evidence that leptin augments inflammatory and profibrogenic responses to hepatic injury [39, 40] whilst downregulation of leptin decreases liver fibrosis [40, 41]. Sympathectomy appears therefore to potentially have both protective anti-inflammatory and potentially antifibrogenic effects. 


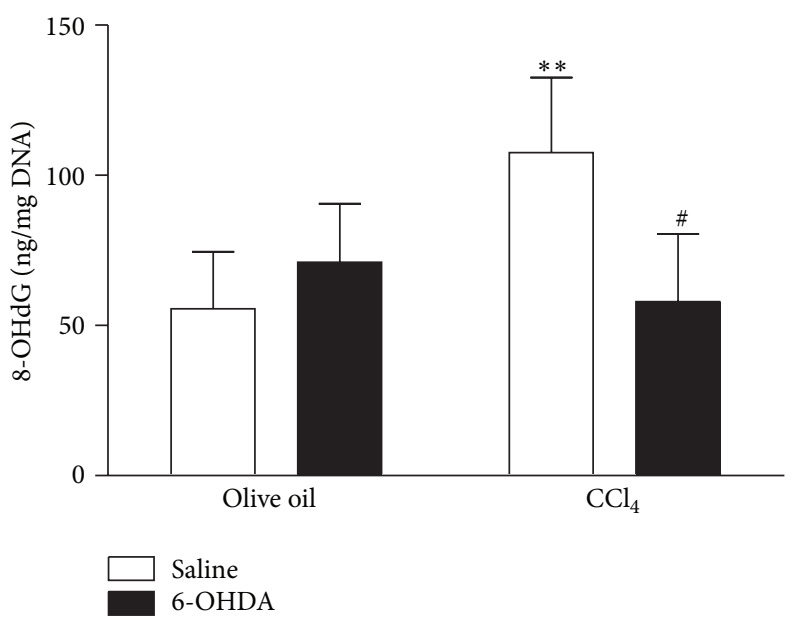

Figure 3: Effect of 6-OHDA on $\mathrm{CCl}_{4}$ induced oxidative DNA damage. Oxidized DNA in liver was measured 24 hours after exposure to olive oil or $\mathrm{CCl}_{4}$ following pretreatment with saline of 6-OHDA. Data plotted are mean and SD ( $n=6$ animals in each group). $* *$ denotes significant differences $(p<0.01)$ compared with the saline + olive oil group. \# denotes significant differences $(p<0.05)$ compared with the saline $+\mathrm{CCl}_{4}$ group.

$\mathrm{CCl}_{4}$ also induced or upregulated the protein expression levels of 5 inflammation-associated chemokines (CCL3, CCL5, CCL9, CCL11, and CXCL11), a response inhibited by pretreatment with 6-OHDA. Increased expression of CCL3 and CCL5 following $\mathrm{CCl}_{4}$ treatment is consistent with previous studies $[42,43]$. To the best of our knowledge, this is the first demonstration of expression of CCL9, a mouse $\mathrm{CC}$ chemokine and strong chemoattractant for bone marrow cells [44], in liver. CCL11 is a known potent inducer of eosinophil chemotaxis and regulates the recruitment to the liver after $\mathrm{CCl}_{4}$ induced hepatic injury to facilitate liver regeneration [45]. CXCL11 release has previously been shown to be induced by oxidative stress exposure [46] and liver ischemia/reperfusion injury [47] supporting the idea that the antioxidant effect of sympathectomy is possibly attributable to the downregulation of CXCL11 and possibly the other cytokines and chemokines studied including GM-CSF [48].

Studies describing an interaction with pharmacological sympathetic blockade have been reported for $\mathrm{CCl}_{4}$. Pretreatment with either prazosin, an $\alpha_{1}$-selective adrenoreceptor antagonist, or yohimbine, an $\alpha_{2}$-selective adrenoreceptor antagonist, abolishes methamphetamine potentiation of $\mathrm{CCl}_{4}$ hepatotoxicity. However, neither prazosin nor yohimbine has any effects on toxicity produced by $\mathrm{CCl}_{4}$ alone $[5,49]$. The ability of phenoxybenzamine, a nonselective, irreversible $\alpha$ adrenergic receptor antagonist, to counteract the hepatotoxic effect of $\mathrm{CCl}_{4}$ by preventing the action of catecholamines [50], has been reported. A similar observation was noticed in the recent study of the interaction between dopaminergic agonist piribedil and $\mathrm{CCl}_{4}$. Administration of piribedil results in amelioration of $\mathrm{CCl}_{4}$ induced liver damage probably due to its $\alpha_{2}$-adrenoceptor antagonist properties to reduce sympathetic outflow and then decrease the extent of lipid peroxidation [51]. Since both phenoxybenzamine and piribedil cross the blood-brain barrier, they would be expected to antagonize pan $\alpha$-or $\alpha_{2}$-adrenoreceptors, respectively, within the central nervous system (CNS). Our findings that phentolamine, a pan $\alpha$-adrenergic antagonist which has no access to the CNS, suppresses hepatic injury through oxidative stress suggest that suppression of antioxidant status by SNS is associated with the peripheral release of catecholamines. Moreover, we show that it is unlikely that the $\beta$-adrenergic signaling modulates $\mathrm{CCl}_{4}$ induced oxidative stress by pretreatment with nadolol. This observation appears to be consistent with a role for isoproterenol, an agonist at both $\beta_{1}$ - and $\beta_{2}$ adrenoreceptors, found to have no effect on potentiation of $\mathrm{CCl}_{4}$ induced hepatotoxicity [52] and may be due to the concept that $\beta$-receptor activation decreases $\mathrm{H}_{2} \mathrm{O}_{2}$ synthesis in hepatocyte plasma membrane $[53,54]$. Although we favor the idea that the $\alpha$-blocker acts directly on hepatocytes we cannot eliminate the potential contribution of catecholamines on blood flow to liver. Activation of the SNS results in production of both "classical" neurotransmitters norepinephrine and epinephrine and cotransmitters such as adenosine triphosphate and adenosine. Hepatocytes express various adrenergic and purinergic receptors that are sensitive to these molecules, and the production of cytokines/chemokines is probably modulated by activation of these receptors [1,55] and not necessarily by adrenergic activity alone.

\section{Conclusions}

In conclusion, we found that sympathectomy or $\alpha$-adrenergic blockade decreased hepatic lipid peroxidation in $\mathrm{CCl}_{4}$ induced liver injury. Our results also suggest that the SNS may regulate inflammatory cytokine and chemokine production following hepatic injury through regulation of lipid peroxidation. This study demonstrates that modulation of the SNS can potentially influence the outcome of acute liver damage and provides a basis to explore the effects of adrenergic modifiers on treatment of drug-induced liver injury in humans. 

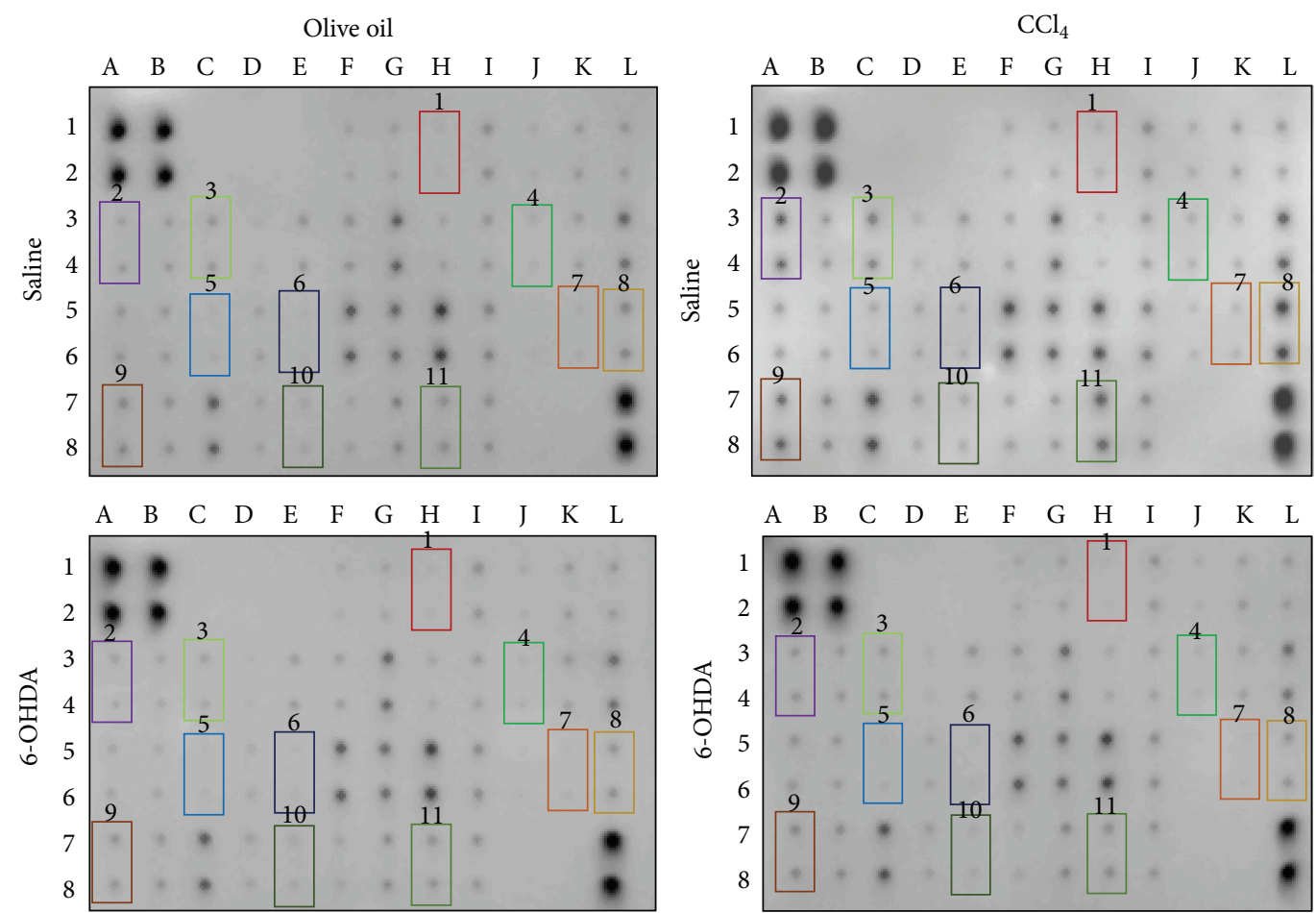

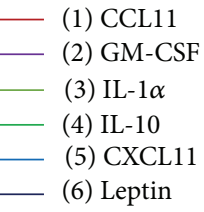

Cytokines

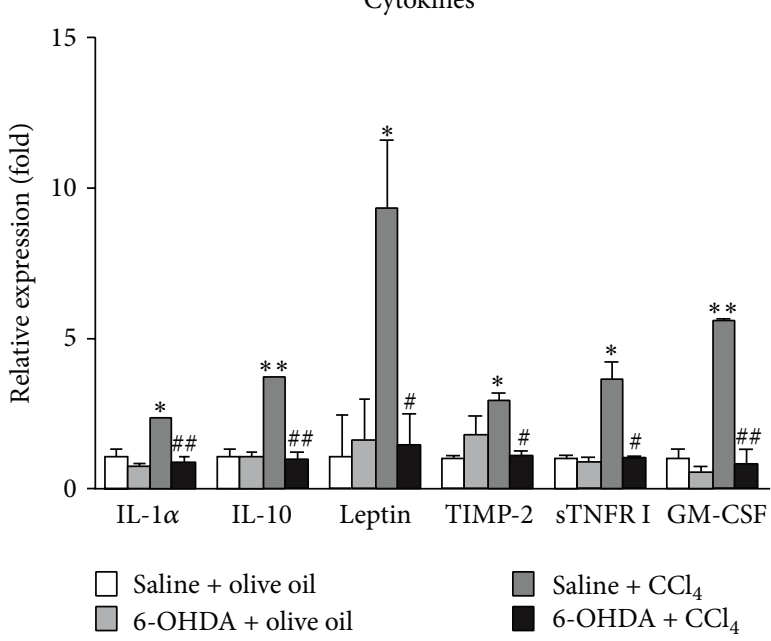

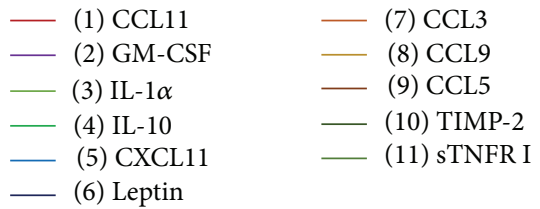

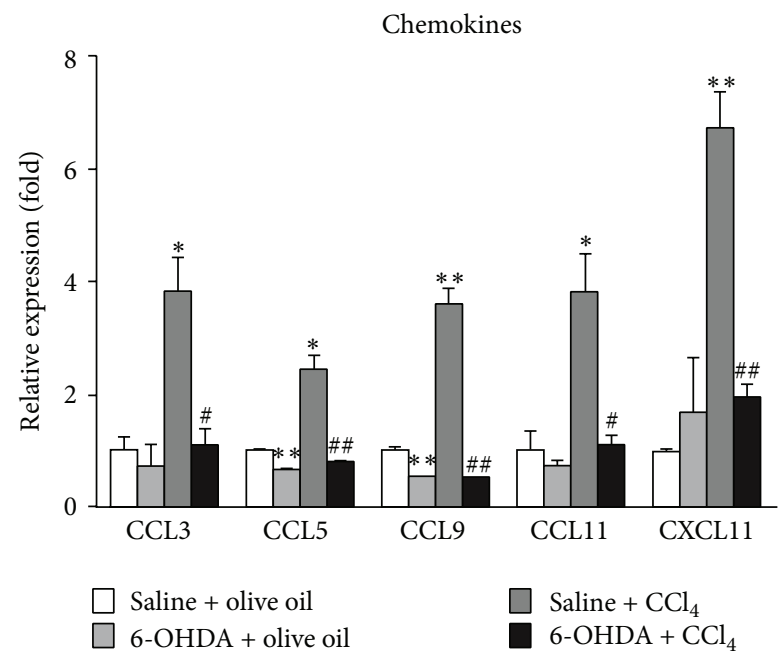

(b)

FIGURE 4: Effect of 6-OHDA on levels of hepatic cytokines and chemokines in the absence and following $\mathrm{CCl}_{4}$ treatment. (a) A cytokine array assay in the liver of the saline + olive oil group, the 6-OHDA + olive oil group, the saline $+\mathrm{CCl}_{4}$ group, and the 6-OHDA $+\mathrm{CCl} 4$ group was measured. Altered cytokines (twofold or more), including IL-1 $\alpha$, IL-10, leptin, TIMP-2, sTNFR I, GM-CSF, CCL3, CCL5, CCL9, CCL11, and CXCL11, are indicated by boxes. (b) The relative density of cytokines and chemokines was normalized with the internal control and expressed as a ratio of the expression level of cytokines and chemokines in each group divided by the expression level in the saline + olive oil group. Each value represents the average of two replicated spots on the membrane. In all figures, $*$ denotes significant differences compared with the saline + olive oil group $(p<0.05)$. $* *$ denotes significant differences compared with the saline + olive oil group $(p<0.01)$. \# denotes significant differences compared with the saline $+\mathrm{CCl}_{4}$ group $(p<0.05)$. \#\# denotes significant differences compared with the saline $+\mathrm{CCl}_{4}$ group $(p<0.01)$. 

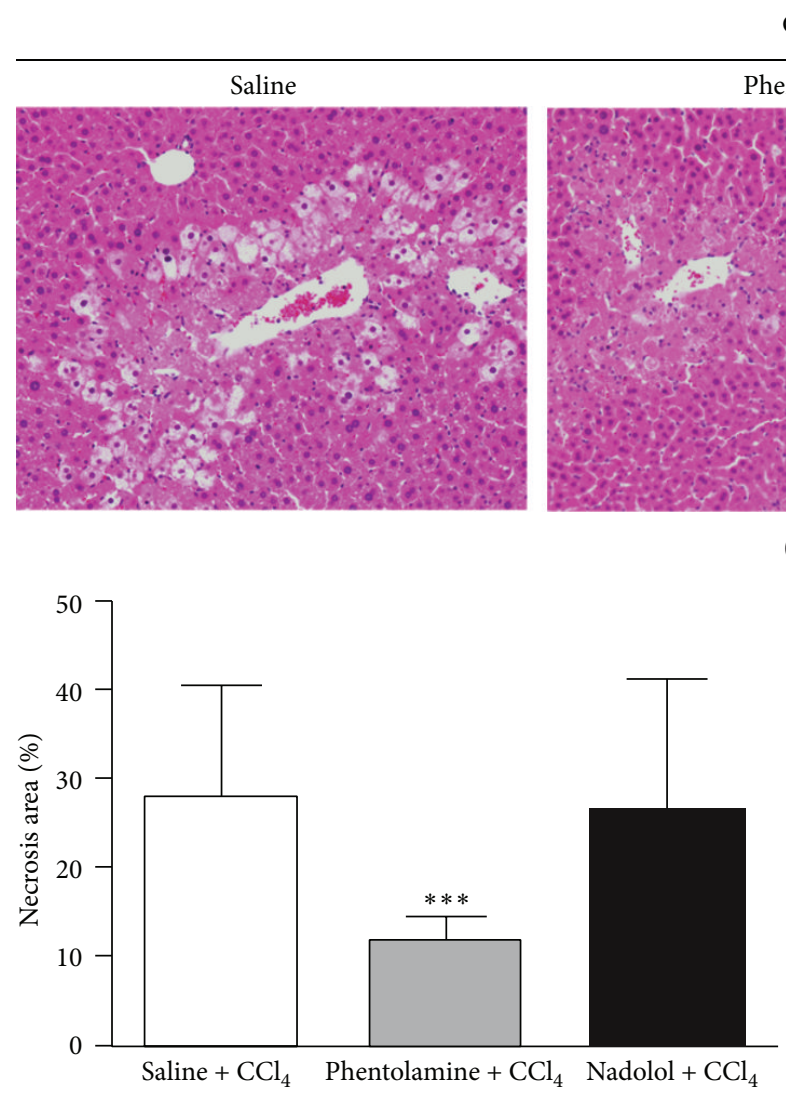

(b)
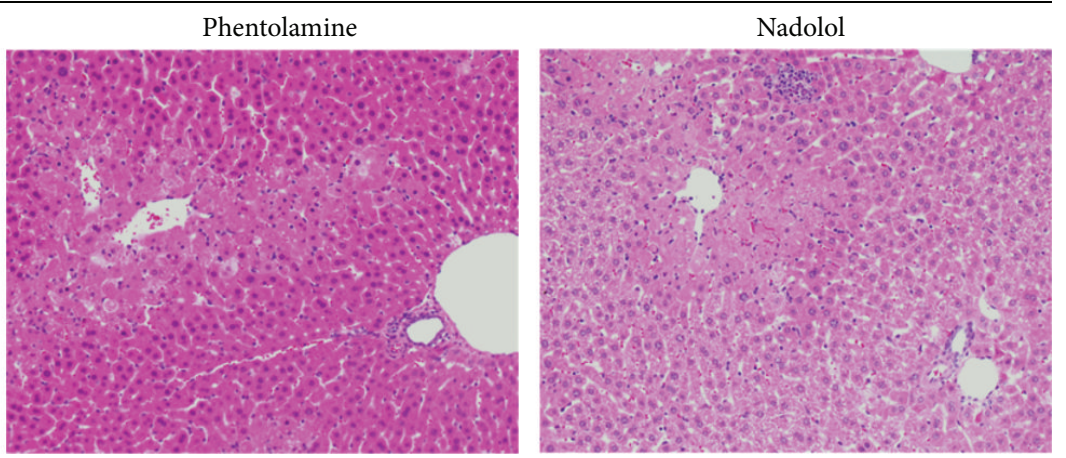

(a)

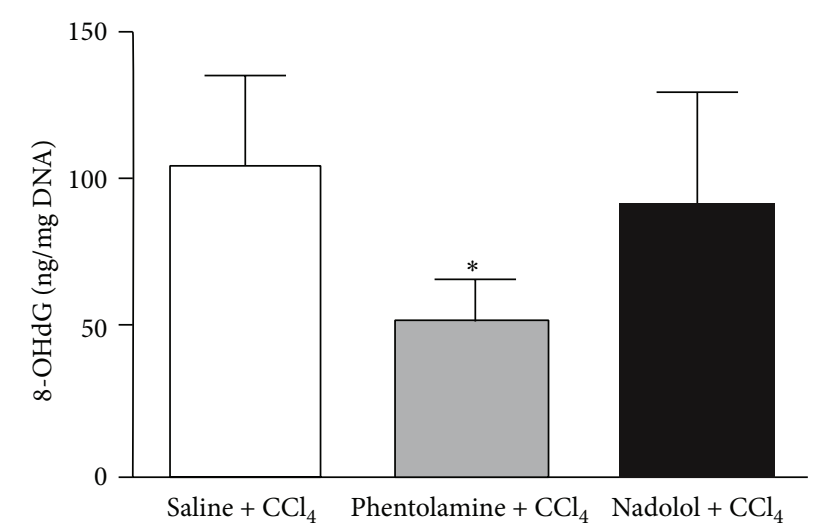

(c)

FIGURE 5: Effect of $\alpha$ - or $\beta$-adrenergic blocker on $\mathrm{CCl}_{4}$ induced hepatic injury and oxidative DNA damage. Histological features (a) and area of necrosis (b) of liver sections stained with hematoxylin and eosin $24 \mathrm{~h}$ after $\mathrm{CCl}_{4}$ treatment. Typical images were selected from each experimental group (original magnification 200x). The saline $+\mathrm{CCl}_{4}$ group showing hepatocellular necrosis; the phentolamine $+\mathrm{CCl}_{4}$ group showing mild hepatocellular necrosis. (c) Oxidized DNA in liver was measured 24 hours after exposure to $\mathrm{CCl}_{4}$ following pretreatment with saline, phentolamine, or nadolol. Data plotted are mean and SD $(n=4$ animals in each group). $*$ denotes significant differences $(p<0.05)$ compared with the saline $+\mathrm{CCl}_{4}$ group. $* * *$ denotes significant differences $(p<0.001)$ compared with the saline $+\mathrm{CCl}_{4}$ group.

\section{Ethical Approval}

All experimental procedures and animal care were performed in accordance with the guidelines approved by the Committee on Institutional Animal Care and Use (IACUC-14-123 and IACUC-15-033) of National Defense Medical Center (Taipei, Taiwan).

\section{Conflict of Interests}

The authors declare no conflict of interests.

\section{Authors' Contribution}

Jung-Chun Lin and Herng-Sheng Lee conceived and designed the experiments. Jung-Chun Lin, Yi-Jen Peng, and Shih-Yu Wang performed the experiments. Jung-Chun Lin, Yi-Jen Peng, Shih-Yu Wang, Mei-Ju Lai, Ton-Ho Young, and Herng-Sheng Lee analyzed the data. Jung-Chun Lin wrote the paper. Donald M. Salter and Herng-Sheng Lee provided advice in designing experiments and writing the paper. All authors have reviewed the paper.

\section{Acknowledgments}

The authors acknowledge the skilled technical assistance of Fang-Show Liou, Yu-Ju Lin, Chih-Shan Chang, Sz-Chi Chen, Ya-Ting Ku, and Chih-Min Kuo. This study was supported in part by grant from Ministry of Science and Technology, Taiwan (MOST 103-2320-B-075B-003), Department of Medical Research of Cardinal Tien Hospital, Taiwan (CTH103-1-2C04), Tri-Service General Hospital, National Defense Medical Center, Taiwan (TSGH-C102-069, TSGH-C103-078, TSGH-C103-080, TSGH-C104-175, TSGH-C104-183, TSGHC105-061, TSGH-C105-074, and TSGH-C105-189), and Medical Affairs Bureau, Ministry of National Defense, Taiwan (MAB-103-066 and MAB-104-089). They would also like to thank Dr. Tung-Hung Chueh for statistical analysis and acknowledge the service of Instrument Center of National Defense Medical Center for the Zeiss LSM 510 Meta inverted 
confocal microscope, especially Po-Li Chen for her technical support.

\section{References}

[1] L. A. Streba, C. C. Vere, A. G. Ionescu, C. T. Streba, and I. Rogoveanu, "Role of intrahepatic innervation in regulating the activity of liver cells," World Journal of Hepatology, vol. 6, no. 3, pp. 137-143, 2014.

[2] A. Geerts, "Hepatic nervous system: foreword," The Anatomical Record Part A: Discoveries in Molecular, Cellular, and Evolutionary Biology, vol. 280, no. 1, pp. 805-806, 2004.

[3] H. Kato and T. Shimazu, "Effect of autonomic denervation on DNA synthesis during liver regeneration after partial hepatectomy," European Journal of Biochemistry, vol. 134, no. 3, pp. 473478, 1983.

[4] C.-T. Hsu, "The role of the autonomic nervous system in chemically-induced liver damage and repair-using the essential hypertensive animal model (SHR)," Journal of the Autonomic Nervous System, vol. 51, no. 2, pp. 135-142, 1995.

[5] L. Dubuisson, A. Desmoulière, B. Decourt et al., "Inhibition of rat liver fibrogenesis through noradrenergic antagonism," Hepatology, vol. 35, no. 2, pp. 325-331, 2002.

[6] B. Pereira, L. F. B. P. Costa-Rosa, E. J. H. Bechara, P. Newsholme, and R. Curi, "Changes in the TBARs content and superoxide dismutase, catalase and glutathione peroxidase activities in the lymphoid organs and skeletal muscles of adrenodemedullated rats," Brazilian Journal of Medical and Biological Research, vol. 31, no. 6, pp. 827-833, 1998.

[7] S. L. Jewett, L. J. Eddy, and P. Hochstein, "Is the autoxidation of catecholamines involved in ischemia-reperfusion injury?" Free Radical Biology and Medicine, vol. 6, no. 2, pp. 185-188, 1989.

[8] J. M. Estrela, F. Gil, J. M. Vila, and J. Vina, "Alpha-adrenergic modulation of glutathione metabolism in isolated rat hepatocytes," The American Journal of Physiology-Endocrinology and Metabolism, vol. 255, no. 6, part 1, pp. E801-E805, 1988.

[9] P. M. Toleikis and D. V. Godin, "Alteration of antioxidant status following sympathectomy: differential effects of modified plasma levels of adrenaline and noradrenaline," Molecular and Cellular Biochemistry, vol. 152, no. 1, pp. 39-49, 1995.

[10] Z. Song, D. Cawthon, K. Beers, and W. G. Bottje, "Hepatic and extra-hepatic stimulation of glutathione release into plasma by norepinephrine in vivo," Poultry Science, vol. 79, no. 11, pp. 16321639, 2000.

[11] L. F. Costa Rosa, R. Curi, C. Murphy, and P. Newsholme, "Effect of adrenaline and phorbol myristate acetate or bacterial lipopolysaccharide on stimulation of pathways of macrophage glucose, glutamine and $\mathrm{O}_{2}$ metabolism. Evidence for cyclic AMP-dependent protein kinase mediated inhibition of glucose-6-phosphate dehydrogenase and activation of NADP+-dependent 'malic' enzyme," Biochemical Journal, vol. 310, part 2, pp. 709-714, 1995.

[12] H. Bo, N. Jiang, G. Ma et al., "Regulation of mitochondrial uncoupling respiration during exercise in rat heart: role of reactive oxygen species (ROS) and uncoupling protein 2," Free Radical Biology and Medicine, vol. 44, no. 7, pp. 1373-1381, 2008.

[13] M. Ishizawa, K. Mizushige, T. Noma et al., "An antioxidant treatment potentially protects myocardial energy metabolism by regulating uncoupling protein 2 expression in a chronic betaadrenergic stimulation rat model," Life Sciences, vol. 78, no. 25, pp. 2974-2982, 2006.
[14] M. L. Kukin, J. Kalman, R. H. Charney et al., "Prospective, randomized comparison of effect of long-term treatment with metoprolol or carvedilol on symptoms, exercise, ejection fraction, and oxidative stress in heart failure," Circulation, vol. 99, no. 20, pp. 2645-2651, 1999.

[15] K. Kawai, F. Qin, J. Shite, W. Mao, S. Fukuoka, and C.-S. Liang, "Importance of antioxidant and antiapoptotic effects of betareceptor blockers in heart failure therapy," The American Journal of Physiology-Heart and Circulatory Physiology, vol. 287, no. 3, pp. H1003-H1012, 2004.

[16] N. Nakamoto, S. Tada, K. Kameyama et al., "A free radical scavenger, edaravone, attenuates steatosis and cell death via reducing inflammatory cytokine production in rat acute liver injury," Free Radical Research, vol. 37, no. 8, pp. 849-859, 2003.

[17] J. D. Morrow, J. A. Awad, T. Kato et al., "Formation of novel non-cyclooxygenase-derived prostanoids (F2-isoprostanes) in carbon tetrachloride hepatotoxicity. An animal model of lipid peroxidation," The Journal of Clinical Investigation, vol. 90, no. 6, pp. 2502-2507, 1992.

[18] J. Liu, K. C. Wu, Y.-F. Lu, E. Ekuase, and C. D. Klaassen, "NRF2 protection against liver injury produced by various hepatotoxicants," Oxidative Medicine and Cellular Longevity, vol. 2013, Article ID 305861, 8 pages, 2013.

[19] F. Zhang, X. Wang, X. Qiu et al., "The protective effect of esculentoside a on experimental acute liver injury in mice," PLoS ONE, vol. 9, no. 11, Article ID e113107, 2014.

[20] J. C. Lin, Y. J. Peng, S. Y. Wang et al., "Role of the sympathetic nervous system in carbon tetrachloride-induced hepatotoxicity and systemic inflammation," PLOS ONE, vol. 10, no. 3, Article ID e0121365, 2015.

[21] H. Terazono, T. Mutoh, S. Yamaguchi et al., "Adrenergic regulation of clock gene expression in mouse liver," Proceedings of the National Academy of Sciences of the United States of America, vol. 100, no. 11, pp. 6795-6800, 2003.

[22] C. A. Camargo Jr., J. F. Madden, W. Gao, R. S. Selvan, and P.-A. Clavien, "Interleukin-6 protects liver against warm ischemia/reperfusion injury and promotes hepatocyte proliferation in the rodent," Hepatology, vol. 26, no. 6, pp. 1513-1520, 1997.

[23] H. Esterbauer, P. Eckl, and A. Ortner, "Possible mutagens derived from lipids and lipid precursors," Mutation Research/ Reviews in Genetic Toxicology, vol. 238, no. 3, pp. 223-233, 1990.

[24] P. M. Eckl, "Genotoxicity of HNE," Molecular Aspects of Medicine, vol. 24, no. 4-5, pp. 161-165, 2003.

[25] A. Ayala, M. F. Muñoz, and S. Argüelles, "Lipid peroxidation: production, metabolism, and signaling mechanisms of malondialdehyde and 4-hydroxy-2-nonenal," Oxidative Medicine and Cellular Longevity, vol. 2014, Article ID 360438, 31 pages, 2014.

[26] L. Knockaert, A. Berson, C. Ribault et al., "Carbon tetrachloride-mediated lipid peroxidation induces early mitochondrial alterations in mouse liver," Laboratory Investigation, vol. 92, no. 3, pp. 396-410, 2012.

[27] L. Moldovan and N. I. Moldovan, "Oxygen free radicals and redox biology of organelles," Histochemistry and Cell Biology, vol. 122, no. 4, pp. 395-412, 2004.

[28] J. Gewiese-Rabsch, C. Drucker, S. Malchow, J. Scheller, and S. Rose-John, "Role of IL-6 trans-signaling in $\mathrm{CCl}_{4}$ induced liver damage," Biochimica et Biophysica Acta-Molecular Basis of Disease, vol. 1802, no. 11, pp. 1054-1061, 2010.

[29] N. Atale, S. Gupta, U. C. S. Yadav, and V. Rani, "Cell-death assessment by fluorescent and nonfluorescent cytosolic and 
nuclear staining techniques," Journal of Microscopy, vol. 255, no. 1, pp. 7-19, 2014.

[30] K. E. McElhanon, C. Bose, R. Sharma, L. Wu, Y. C. Awasthi, and S. P. Singh, "Gsta4 null mouse embryonic fibroblasts exhibit enhanced sensitivity to oxidants: role of 4-hydroxynonenal in oxidant toxicity," Open Journal of Apoptosis, vol. 2, no. 1, pp. 111, 2013.

[31] O. Sommerburg, T. Grune, S. Klee, F. R. Ungemach, and W. G. Siems, "Formation of 4-hydroxynonenal and further aldehydic mediators of inflammation during bromotrichlorornethane treatment of rat liver cells," Mediators of Inflammation, vol. 2, no. 1, pp. 27-31, 1993.

[32] L. Milkovic, A. Cipak Gasparovic, and N. Zarkovic, "Overview on major lipid peroxidation bioactive factor 4-hydroxynonenal as pluripotent growth-regulating factor," Free Radical Research, vol. 49, no. 7, pp. 850-860, 2015.

[33] U. C. S. Yadav and K. V. Ramana, "Regulation of NF- $\kappa$ Binduced inflammatory signaling by lipid peroxidation-derived aldehydes," Oxidative Medicine and Cellular Longevity, vol. 2013, Article ID 690545, 11 pages, 2013.

[34] T. Sakurai, G. He, A. Matsuzawa et al., "Hepatocyte necrosis induced by oxidative stress and IL-1 alpha release mediate carcinogen-induced compensatory proliferation and liver tumorigenesis," Cancer Cell, vol. 14, no. 2, pp. 156-165, 2008.

[35] Y. Yamada and N. Fausto, "Deficient liver regeneration after carbon tetrachloride injury in mice lacking type 1 but not type 2 tumor necrosis factor receptor," The American Journal of Pathology, vol. 152, no. 6, pp. 1577-1589, 1998.

[36] E. Roeb, E. Purucker, B. Breuer et al., "TIMP expression in toxic and cholestatic liver injury in rat," Journal of Hepatology, vol. 27, no. 3, pp. 535-544, 1997.

[37] M. A. Ajakaiye, A. Jacob, R. Wu et al., "Upregulation of Kupffer cell $\alpha 2 \mathrm{~A}$-Adrenoceptors and downregulation of MKP-1 mediate hepatic injury in chronic alcohol exposure," Biochemical and Biophysical Research Communications, vol. 409, no. 3, pp. 406411, 2011.

[38] B. Sigala, C. McKee, J. Soeda et al., "Sympathetic nervous system catecholamines and neuropeptide Y neurotransmitters are upregulated in human NAFLD and modulate the fibrogenic function of hepatic stellate cells," PLoS ONE, vol. 8, no. 9, Article ID e72928, 2013.

[39] K. Ikejima, H. Honda, M. Yoshikawa et al., "Leptin augments inflammatory and profibrogenic responses in the murine liver induced by hepatotoxic chemicals," Hepatology, vol. 34, no. 2, pp. 288-297, 2001.

[40] J. A. Handy, P. P. Fu, P. Kumar et al., "Adiponectin inhibits leptin signalling via multiple mechanisms to exert protective effects against hepatic fibrosis," Biochemical Journal, vol. 440, no. 3, pp. 385-395, 2011.

[41] B. Lu, L. Yu, S. Li, S. Si, and Y. Zeng, "Alleviation of CCl4induced cirrhosis in rats by tetramethylpyrazine is associated with downregulation of leptin and TGF- $\beta 1$ pathway," Drug and Chemical Toxicology, vol. 33, no. 3, pp. 310-315, 2010.

[42] A. Nellen, D. Heinrichs, M.-L. Berres et al., "Interference with oligomerization and glycosaminoglycan binding of the chemokine CCL5 improves experimental liver injury," PLoS ONE, vol. 7, no. 5, Article ID e36614, 2012.

[43] R. G. Gieling, A. M. Elsharkawy, J. H. Caamã No et al., "The c-Rel subunit of nuclear factor- $\kappa \mathrm{b}$ regulates murine liver inflammation, wound-healing, and hepatocyte proliferation," Hepatology, vol. 51, no. 3, pp. 922-931, 2010.
[44] M. Yang and P. R. Odgren, "Molecular cloning and characterization of rat CCL9 (MIP-1 $\gamma$ ), the ortholog of mouse CCL9," Cytokine, vol. 31, no. 2, pp. 94-102, 2005.

[45] Y. P. S. Goh, N. C. Henderson, J. E. Heredia et al., "Eosinophils secrete IL-4 to facilitate liver regeneration," Proceedings of the National Academy of Sciences of the United States of America, vol. 110, no. 24, pp. 9914-9919, 2013.

[46] J. Øvrevik, M. Refsnes, P. Schwarze, and M. Låg, “The ability of oxidative stress to mimic quartz-induced chemokine responses is lung cell line-dependent," Toxicology Letters, vol. 181, no. 2, pp. 75-80, 2008.

[47] Y. Zhai, X.-D. Shen, W. W. Hancock et al., "CXCR3 ${ }^{+}$CD $4^{+}$T cells mediate innate immune function in the pathophysiology of liver ischemia/reperfusion injury," Journal of Immunology, vol. 176, no. 10, pp. 6313-6322, 2006.

[48] H. Nagashima, K. Nakamura, and T. Goto, "Rubratoxin B induced the secretion of hepatic injury-related colony stimulating factors in human hepatoma cells," Toxicology Letters, vol. 145, no. 2, pp. 153-159, 2003.

[49] S. M. Roberts, R. D. Harbison, and R. C. James, "Methamphetamine potentiation of carbon tetrachloride hepatotoxicity in mice," Journal of Pharmacology and Experimental Therapeutics, vol. 271, no. 2, pp. 1051-1057, 1994.

[50] T. M. Brody, D. N. Calvert, and A. F. Schneider, "Alteration of carbon tetrachloride-induced pathologic changes in the rat by spinal transection, adrenalectomy and adrenergic blocking agents," Journal of Pharmacology and Experimental Therapeutics, vol. 131, no. 3, pp. 341-345, 1961.

[51] O. M. E. Abdel-Salam, A. A. Sleem, and N. Shafee, "The dopamine agonist piribedil exerts hepatoprotective effects on carbon tetrachloride-induced hepatic damage," Comparative Clinical Pathology, vol. 22, no. 3, pp. 413-419, 2013.

[52] S. M. Roberts, R. D. Harbison, J. E. Seng, and R. C. James, "Potentiation of carbon tetrachloride hepatotoxicity by phenylpropanolamine," Toxicology and Applied Pharmacology, vol. 111, no. 2, pp. 175-188, 1991.

[53] A. Díaz-Cruz, R. Guinzberg, R. Guerra et al., "Adrenaline stimulates $\mathrm{H}_{2} \mathrm{O}_{2}$ generation in liver via NADPH oxidase," Free Radical Research, vol. 41, no. 6, pp. 663-672, 2007.

[54] A. Diaz-Cruz, M. M. Vilchis-Landeros, R. Guinzberg, R. Villalobos-Molina, and E. Piña, "NOX2 activated by $\alpha_{1}$-adrenoceptors modulates hepatic metabolic routes stimulated by $\beta$ adrenoceptors," Free Radical Research, vol. 45, no. 11-12, pp. 1366-1378, 2011.

[55] D. S. Emmett, A. Feranchak, G. Kilic et al., "Characterization of ionotrophic purinergic receptors in hepatocytes," Hepatology, vol. 47, no. 2, pp. 698-705, 2008. 


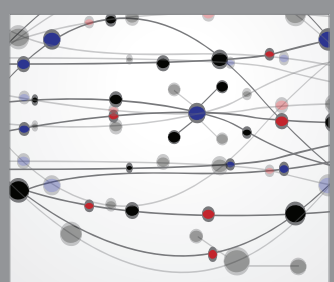

The Scientific World Journal
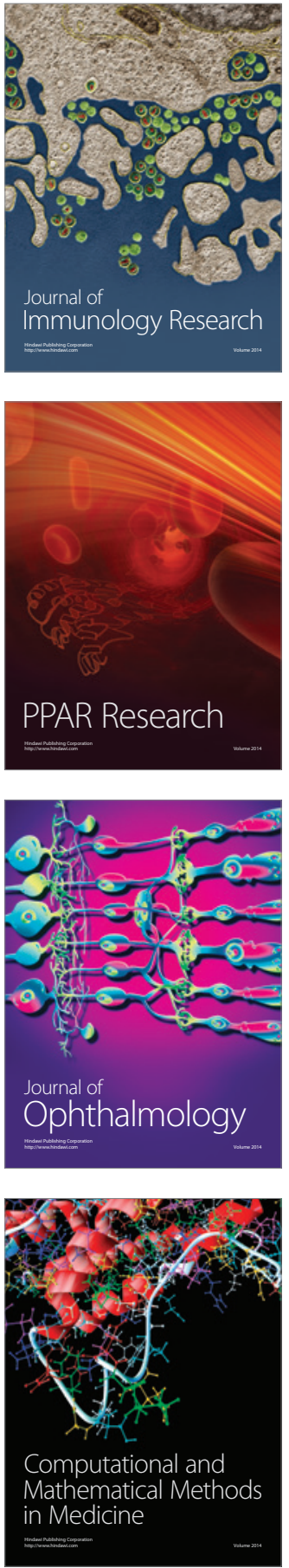

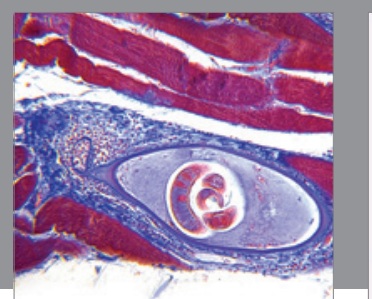

Gastroenterology Research and Practice

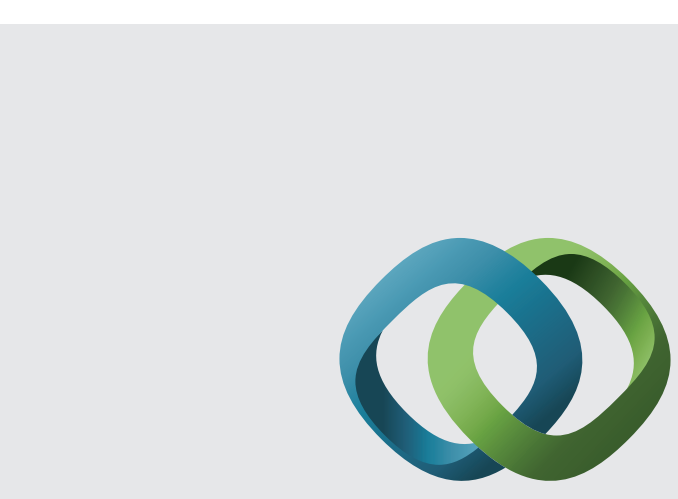

\section{Hindawi}

Submit your manuscripts at

http://www.hindawi.com
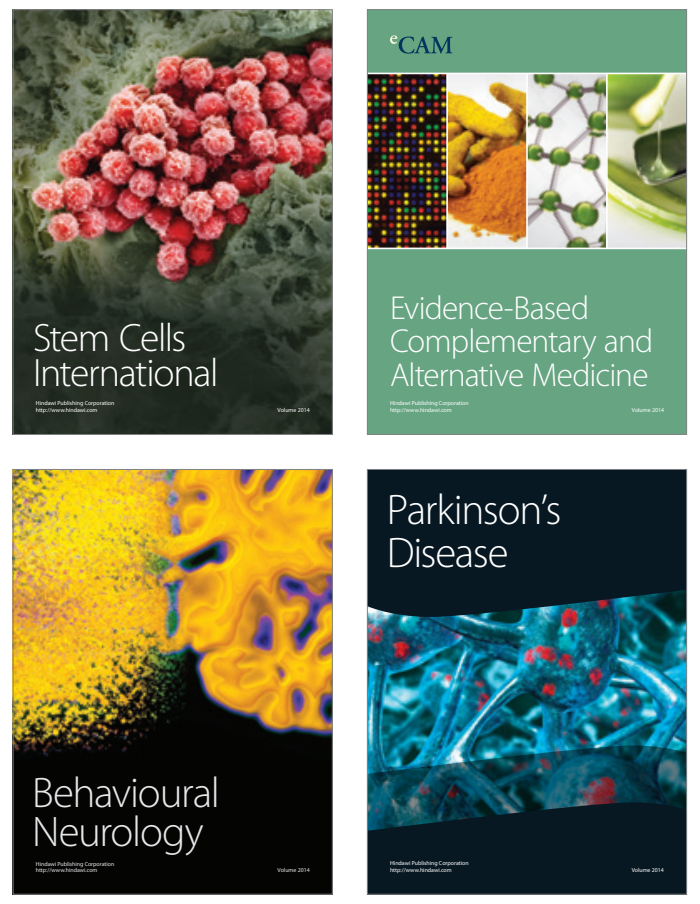
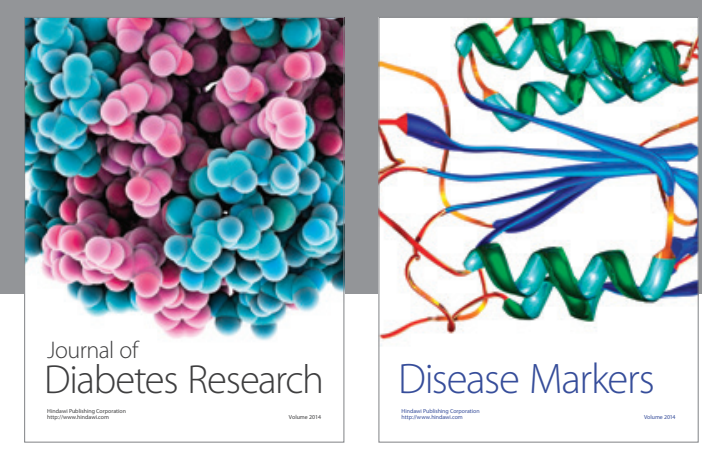

Disease Markers
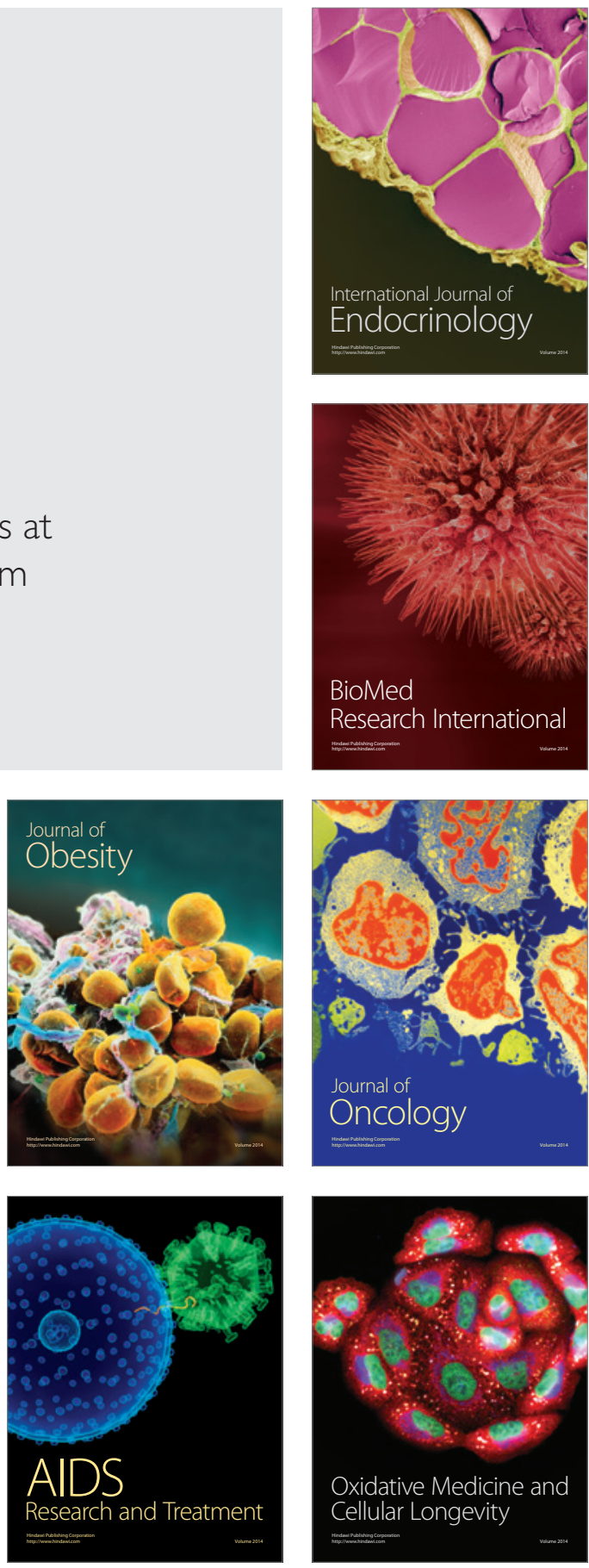